\title{
Experimental study of the velocity field induced by a propeller jet in an inland-ship model and the related bed scour
}

\author{
Francisco Núñez-González ${ }^{1, *}$,Katinka Koll ${ }^{1}$, and Detlef Spitzer $^{2}$ \\ ${ }^{1}$ Leichtweiß-Institut für Wasserbau, Technische Universität Braunschweig, Beethovenstr. 51a, 38106 \\ Braunschweig, Germany \\ ${ }^{2}$ Bundesanstalt für Wasserbau, Kußmaulstr. 17, 76187 Karlsruhe, Germany
}

\begin{abstract}
The highly turbulent flow induced by ship propellers has a great potential to scour the alluvial bottom of navigational rivers and canals. Characterization of the complex flow field behind propellers is essential for forecasting the scouring action. In this study the velocity field and scour induced by two standard arrangements of propeller, nozzle and rudder from inland vessels are investigated experimentally with a ship model on a scale of 1:16. There are two objectives: first, to identify the influence of the ship stern on the flow field, and second, to assess induced scour depths in relation to maximum current velocities close to the bottom. It is found that the equilibrium scour depths for the two propeller arrangements are of the same order of magnitude, but that the time development of scour is different. The differences can be explained by the converging trend of the flow velocities at the bottom level for the two situations, when the vertical distance between the propeller and the bottom is high. It is also shown that existing relations for the velocity field require amendment when the propeller is ducted, and for adequately considering the effect of the ship stern and rudder type.
\end{abstract}

\section{Introduction}

Ship propellers generate high-velocity turbulent jets that may cause deep erosion on alluvial beds and damage to quay structures and banks. Forecasting of damages and design of appropriate protection require understanding of the interaction between the flow field in the propeller jet and the characteristics of the streambed sediment. Different formulas for the estimation of scour induced by ship propellers can be found in literature (e.g., [1-3]). In such formulas, the basis for the characterization of the jet action over the bed surface is the calculation of the maximum axial flow velocity induced by the jet on the channel bed. Accordingly, reliable estimations of ship propeller-induced scouring require accurate estimates of this velocity.

The velocity field in the propeller wash depends on many boundary conditions, such as propeller characteristics, number of propellers, engine power, rudder arrangement, underkeel clearance, the shape of the stern and the draught of the ship, among many others $([1,4-$

* Corresponding author: f.nunez-gonzalez@,tu-braunschweig.de 
7]). Existing relations for describing the velocity field include empirical factors for given boundary conditions and vessel types. Nevertheless, some boundary conditions can only be considered to a certain degree due to limited information provided by available empirical test results. To this respect, the aim of this work is to identify the effect of the ship stern and different combinations of propeller, rudder and Kort nozzle arrangements, on the jet velocity distribution of inland vessels in a manoeuvring situation, and evaluate the influence of the maximum near bed flow velocity on the corresponding scour depth.

The flow field and scour induced by two different propellers were studied experimentally, using a scaled model of inland vessels commonly found on German waterways. The two propellers used were a Kaplan propeller, provided with a Kort nozzle and a double rudder, and a Wageningen B-series propeller, accompanied with a central rudder. According to the classification of different propeller jet dispersion situations in [7], these two propeller arrangements correspond to the declared standard situation 1 (SS1) and standard situation 2 (SS2). SS1 and SS2 describe situations with no lateral and longitudinal limits to the jet dispersion, with SS2 considering the splitting of the jet by a central rudder into a jet directed towards the channel bed and one directed towards the water surface, and SS1 considering no jet splitting. Standard situations 3 and 4, not considered in this work, correspond to conditions when the dispersion of the jet is affected by quay structures.

In this work results from an extensive experimental campaign are presented, concerning scour development, and flow velocity measurements close to the propeller face and close to the bed surface, for SS1 and SS2. In the two situations the model propeller is run with and without hull ahead of it.

\subsection{Flow field induced by ship propellers}

Two main regions can be identified within the flow field behind a propeller jet: a region of flow establishment and a region of established flow. According to different authors, the maximum velocity, defined as the initial velocity, induced jet velocity or efflux velocity $u_{0}$, is constant in the potential core along the region of flow establishment $([4,5,7])$. From the Rankine's axial momentum theory $([4,5,8])$, considering a still water situation, $u_{0}$ can be computed with

$$
u_{0}=\frac{2}{\sqrt{\pi}} n_{P} D_{P} \sqrt{K_{T}} \frac{D_{P}}{D_{0}}
$$

where $n_{P}$ is the number of propeller revolutions per unit time, $D_{P}$ is the propeller diameter, $K_{T}$ is the thrust coefficient, and $D_{0}$ is the diameter of the contracted section behind the propeller. The contraction is caused by the high-pressure gradient induced by the propeller. For non-ducted propellers, it can be derived from the theory that $D_{P} / D_{0}=2^{1 / 2}$; while for ducted-propellers it is commonly assumed that there is no jet contraction, i.e., that $D_{0}=D_{P}$ $([4,5])$. According to [4], $u_{0}$ is fully developed only in a distance of $x / D_{P}=0.5$ behind the propeller, where $x$ is the horizontal coordinate along the jet axis, with the origin in the propeller plane.

In the region of established flow, in analogy to the diffusion of free submerged jets ([9]), the axial velocity field can be described according to the normal probability function as $([5])$

$$
\frac{u_{x, r}}{u_{0}}=\frac{1}{2 C} \frac{D_{0}}{x} \exp -\left(\frac{r^{2}}{2 C^{2} x^{2}}\right)
$$

where $u_{x, r}$ is the axial velocity at a horizontal distance $x$ from the propeller plane, and at a radial distance $r$ from the rotating axis, and $C$ is a constant. 
The most relevant jet velocity for the beginning of scour is the maximum velocity close to the bed level. Making $r=h_{p}$, with $h_{p}$ being the height of the propeller axis above the bed, by differentiating Eq. (2) with respect to $x$, the position $x_{u b m a x}$ of the maximum jet velocity on the bed, for a fixed $h_{p}$ value, becomes $x_{u b \max }=h_{p} / C$. Using this relation in Eq. (2), the maximum velocity on the bed can be determined by

$$
\frac{u_{b \max }}{u_{0}}=\frac{1}{2} \frac{D_{0}}{h_{p}} \exp -\left(\frac{1}{2}\right)
$$

Eq. (3) is valid for a free turbulent jet. In reality, the dispersion of the jet is influenced by the stern shape and type of rudder. Accordingly, some authors have suggested the following relation, as a simplified method to calculate the maximum near-bed velocity $([10,11,7])$ :

$$
\frac{u_{b \max }}{u_{0}}=E \frac{D_{P}}{h_{p}}
$$

where $E$ is a constant dependent on the stern shape and rudder configuration. $E$-values suggested by different authors are summarized in Table 1 .

Table 1. Suggested values for E-coefficient found in literature (taken from [12]).

\begin{tabular}{|l|l|c|}
\hline Source & \multicolumn{1}{|c|}{ Configuration } & $\boldsymbol{E}$ \\
\hline$[7]$ & Slender sterns with a central rudder & 0.71 \\
\hline$[11]$ & Twin screw vessel with Kort nozzles, central rudder and tunnel stern & 0.58 \\
\hline$[13]$ & SS2, unducted propeller & 0.51 \\
\hline$[10]$ & Ducted single screw, trawler, central rudder & 0.47 \\
\hline$[7]$ & Slender sterns without a central rudder & 0.42 \\
\hline$[13]$ & SS1, ducted propeller & 0.38 \\
\hline$[11,13]$ & Propeller in Kort nozzle (unbounded jet) & 0.30 \\
\hline$[13]$ & SS1, unducted propeller & 0.27 \\
\hline$[7,10]$ & Modern inland navigation craft with a tunnel stern and twin rudders & 0.25 \\
\hline$[11,13]$ & Free propeller (unbounded jet) & 0.21 \\
\hline
\end{tabular}

\section{Experimental methods}

\subsection{Experimental setup}

Experiments were conducted at the hydraulics laboratory of the Leichtweiß-Institut für Wasserbau of the Technische Universität Brauschweig, Germany, in a rectangular basin of $5 \mathrm{~m}$ width, $2 \mathrm{~m}$ height and $15 \mathrm{~m}$ length. A false bottom made of wood plates of $3.6 \mathrm{~m}$ width, $0.33 \mathrm{~m}$ height and $3 \mathrm{~m}$ length was installed, which contains a $1.24 \mathrm{~m}$ wide recess area that is filled with sediment for mobile-bed experiments, or covered with a flat plate for fixed bed runs.

The model vessel used for the experiments, a large inland vessel (in German: Großmotorschiff, GMS), is scaled 1:16, and is $0.7 \mathrm{~m}$ wide, $0.4 \mathrm{~m}$ deep and $5 \mathrm{~m}$ long. The diameter of the two propellers used and their corresponding hubs are $11 \mathrm{~cm}$ and $2 \mathrm{~cm}$, while the rudders are $11.5 \mathrm{~cm}$ high and $9.25 \mathrm{~cm}$ long. Images of the ship model and the stern-rudder-nozzle configurations can be found in [12]. The rudders were always kept parallel to the ship axis. The blade area ratio is 0.55 and 0.70 , for the Kaplan and the Wageningen propellers, respectively, and the thrust coefficients from open water tests, for advance coefficient $\mathrm{J}=0$, are 0.55 for the Kaplan propeller with or without nozzle, and 0.70 
for the Wageningen propeller. For the set of experiments considered here, the rotation speed of the propellers was kept constant to $1,340 \mathrm{rpm}$. During the experiments the ship was installed over the recess area limited by the wooden false bottom, and it was firmly attached to a metal frame to prevent its movement around the vertical and transverse axis.

\subsection{Scour experiments}

For the scour experiments the recess area in the middle of the basin was filled with coarse quartz sand $\left(d_{50}=0.8 \mathrm{~mm} ; \sigma_{g}=\left(d_{84} / d_{16}\right)^{0.5}=1.3\right)$ of density $\rho_{s}=2650 \mathrm{~kg} / \mathrm{m}^{3}$. Following the Froude scale, this material scales to a medium gravel in prototype; however, according to previous experiences with ship propeller scour ([e.g., 14]), it can be expected that, especially for low Reynolds numbers relative to the Shields curve, the scaled scour depths would be lower in nature than in the model. The experiments were intended to characterize the time-dependent development of bed scour in a manoeuvring situation, e.g. with the motor on and the ship stationary. Accordingly, each experiment was initiated with a flat bed, and the elapsed time was registered from the moment when the propeller began to rotate. Two types of experiments were performed. For the first type, designated in this work as Type I, the propeller drive was stopped at predefined elapsed times, up to a total load duration of $6 \mathrm{~h}$, to measure the maximum scour depth with a point gauge. After each measurement, the motor was turned on again and the experiment continued. The second type of experiments, designated in this work as Type II, were long-time experiments for which the first scour depth measurements were performed for elapsed-times equal or larger than $3.5 \mathrm{~h}$, and then for few other intervals up to $24 \mathrm{~h}$. More details on the scour experiments can be found in [12]. The experiments referred to here, which were conducted with the Kaplan propeller with double rudder $(\mathrm{KD})$, and the Wageningen propeller with central rudder (WZ), i.e., standard situations SS1 and SS2, respectively, were based exclusively on the following conditions: a water depth of $h=21.9 \mathrm{~cm}$, ship draught of $D_{r}=17.9 \mathrm{~cm}$, and a distance of the propeller axis to the channel bed of $h_{p}=9.5 \mathrm{~cm}$.

\subsection{Velocity field}

Flow velocity measurements were intended to characterize $u_{0}$ and $u_{b \max }$, in order to obtain values of the $E$-coefficient for different boundary conditions. Six boundary conditions, regarding the propeller arrangement, were selected for the objectives of this paper to identify the effect of the ship stern on the velocity field. The selected boundary conditions are given in Table 2. For these experiments the recess area in the middle of the basin was covered with a plywood plate, to which a single layer of fine gravel $\left(d_{50}=3.7 \mathrm{~mm}\right.$; $\left.\sigma_{g}=\left(d_{84} / d_{16}\right)^{0.5}=1.4\right)$ was glued.

Table 2. Propeller configurations considered for the velocity measurements.

\begin{tabular}{|c|l|l|}
\hline Propeller & \multicolumn{1}{|c|}{ Geometrical variant } & Nomenclature \\
\hline \multirow{3}{*}{ Kaplan } & No ship stern, no nozzle, no rudder & KoO_oS \\
\cline { 2 - 3 } & No ship stern, with nozzle, with double rudder & KD_oS \\
\cline { 2 - 3 } & With ship stern, with nozzle, with double rudder(SS1) & KD \\
\hline \multirow{3}{*}{ Wageningen } & No ship stern, no nozzle, no rudder & WO_oS \\
\cline { 2 - 3 } & No ship stern, no nozzle, with central rudder & WZ_oS \\
\cline { 2 - 3 } & With ship stern, no nozzle, with central rudder (SS2) & WZ \\
\hline
\end{tabular}

For characterizing $u_{0}$, measurements with a constant water depth and draught were carried out on a vertical plane at $x \approx 0.5 D_{P}$ behind the propeller, using a Prandtl tube $(8 \mathrm{~mm}$ outside and $2 \mathrm{~mm}$ inside diameters). The distance between the measuring points was $1 \mathrm{~cm}$. 
For the identification of $u_{b \max }$, jet velocities $12 \mathrm{~mm}$ above the bed surface were measured with an automatically controlled rack of nine micro-current meters (NIXON, Streamflo Velocity Meter 403), at nine different positions during each experiment. In this manner, a raster of 81 points was obtained, with a separation of $5 \mathrm{~cm}$ along the jet axis and $7 \mathrm{~cm}$ laterally, encompassing a total area of $75 \times 40 \mathrm{~cm}^{2}$. Operation range of the microcurrent meters is between 5 to $120 \mathrm{~cm} / \mathrm{s}$. All probes were connected to a computer which registered the signal automatically. Velocity at each position (i.e., the raster points) was recorded for 3 minutes. The measurements referred to here consider the six combinations of ship draught $D_{r}$, and water depth $h$ listed in Table 3. In this table the corresponding values for $h_{p}$, defined as the height of the propeller axis above the measuring point, are shown as well. For free propeller experiments (KoO_oS and WO_oS) only boundary condition 2 was tested.

Table 3. Boundary conditions for experiments to characterize the velocity field.

\begin{tabular}{|c|c|c|c|}
\hline $\begin{array}{c}\text { Boundary condition } \\
\text { Nr. }\end{array}$ & Draught $\boldsymbol{D}_{\boldsymbol{r}}[\mathbf{c m}]$ & Water depth $\boldsymbol{h}[\mathbf{c m}]$ & $\boldsymbol{h}_{\boldsymbol{p}}[\mathbf{c m}]$ \\
\hline 1 & 17.9 & 22.0 & 8.4 \\
\hline 2 & 17.9 & 25.8 & 12.2 \\
\hline 3 & 17.9 & 29.5 & 15.9 \\
\hline 4 & 17.9 & 33.4 & 19.8 \\
\hline 5 & 21.8 & 25.8 & 8.4 \\
\hline 6 & 21.8 & 34.9 & 17.5 \\
\hline
\end{tabular}

\section{Results}

\subsection{Scour}

Time series of the maximum scour depths $\varepsilon_{s}$, normalized by the propeller diameter, are shown in Fig. 1. For both KD and WZ variants, the run Type I was performed twice for identical boundary conditions and load-periods (runs A and B, in Fig. 1). For WZ there is a good agreement between both runs, proving the reproducibility of the conducted experiments. Conversely, the scour depths for KD in run A is between 2 and $4 \mathrm{~cm}$ higher than for run B, for the same elapsed-times. Still, for both $\mathrm{KD}$ and $\mathrm{WZ}$ variants the increments of scour with time are roughly the same for the corresponding A and B runs. The gradient is almost constant for $\mathrm{KD}$, while for $\mathrm{WZ}$ there is an increase in gradient at $\mathrm{t}=630 \mathrm{~s}$.

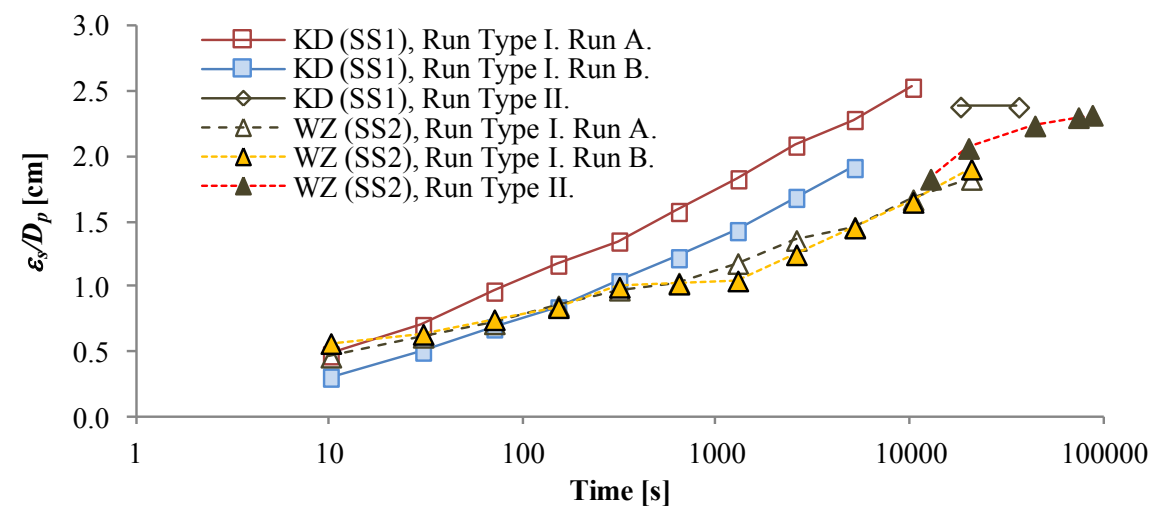

Fig. 1. Ratio of measured maximum scour depths to propeller diameter as a function of time. 
For Type II runs, the scour depths for the longest elapsed-times are almost of the same magnitude for $\mathrm{KD}$ and $\mathrm{WZ}$. For KD, the maximum scour depth is practically the same at $t=5 \mathrm{~h}$ as 5 hours later, evidencing that a stable scour depth was reached. Conversely, for WZ, between $t=5.5 \mathrm{~h}$ and $t=12 \mathrm{~h}$ there is still an increment of almost $2 \mathrm{~cm}$ on the scour depth; but between $t=20 \mathrm{~h}$ and $t=24 \mathrm{~h}$, the increment is as low as $2 \mathrm{~mm}$, indicating that stable conditions were practically reached. Important is that, even when the scour depths were mostly larger for KD than for WZ during runs Type II, the final scour depths obtained were very similar, being $26.2 \mathrm{~cm}$ for KD at $t=10 \mathrm{~h}$, and $25.5 \mathrm{~cm}$ for WZ at $t=24 \mathrm{~h}$.

\subsection{Efflux velocity $u_{0}$}

The velocity distributions measured close to the propeller plane are shown in Fig. 2. A visual inspection reveals that the distributions without ship stern $\left(\mathrm{KoO} \_\mathrm{oS}, \mathrm{KD} \_\mathrm{oS}\right.$, WO_oS, WZ_oS) are approximately symmetrical, with concentric rings of same axial velocity around the propeller tip. The symmetry and the concentric rings are broken for the two distributions with ship stern (KD, WZ). A closer inspection of the distributions shows that the magnitude of velocities in the region of maximum values is lower for conditions with nozzle than without nozzle; for all the distributions without nozzle this region is characterized by velocities larger than $2.4 \mathrm{~m} / \mathrm{s}$ (orange and red in the colour scale), while velocities lower than $2.4 \mathrm{~m} / \mathrm{s}$ (yellow and green in the colour scale) occur in this region for the two conditions with nozzle.
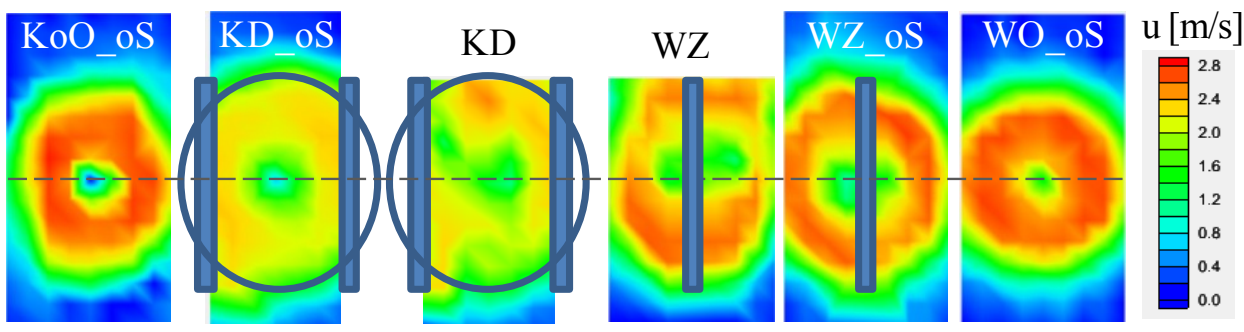

Fig. 2. Flow fields close to the propeller plane.

Table 4. Experimental results for velocity measurements and comparison with literature.

\begin{tabular}{|c|c|c|c|c|}
\hline \multirow[b]{2}{*}{ Variant } & \multicolumn{2}{|r|}{$u_{0}[\mathrm{~m} / \mathbf{s}]$} & \multicolumn{2}{|c|}{$E$-coefficient } \\
\hline & Measured & Computed (Eq. (1)) & $\begin{array}{c}\text { Fit from } \\
\text { measurements }\end{array}$ & $\begin{array}{c}\text { From literature } \\
\text { (Table 1) }\end{array}$ \\
\hline KoO_oS & 2.63 & 2.68 & 0.25 & 0.21 \\
\hline $\mathrm{KD}$ oS & 2.26 & 1.89 & 0.54 & 0.30 \\
\hline $\mathrm{KD}(\mathrm{SS} 1)$ & 2.15 & 1.89 & 0.38 & 0.38 \\
\hline WO_oS & 2.72 & 2.62 & 0.24 & 0.21 \\
\hline WZ_oS & 2.51 & 2.62 & 0.52 & -- \\
\hline WZ (SS2) & 2.51 & 2.62 & 0.31 & 0.51 \\
\hline
\end{tabular}

No standard method exists to determine $u_{0}$ from measurements. Particularly for the nonsymmetrical distributions, it is not straightforward to define which value of velocity should be considered as the efflux velocity $u_{0}$. Two methods were applied here. The first consisted in dividing the distribution in radial segments, and obtaining the maximum velocity within each segment; the average of these velocities was taken as the efflux velocity. The second method consisted in fitting a Gaussian-type curve to the distribution, and considering the peak velocity in the curve as the efflux velocity. $u_{0}$ values obtained with this method were $2 \%$ higher than with the radial segments method. The values obtained with the Gauss distribution are shown in Table 4 as well as the values calculated with Eq. (1). For non- 
ducted propellers, the difference between computed and measured $u_{0}$ was lower than $5 \%$, evidencing a good performance of Eq. (1), even for conditions with ship stern. Conversely, for the two conditions with nozzle, Eq. (1) underestimated $u_{0}$ by $12 \%$ and $16 \%$, suggesting that this equation needs improvement to adequately consider ducted propellers.

\subsection{Maximum velocity close to the bed $\boldsymbol{u}_{b \max }$}

The maximum velocities identified from the measurements close to the bed level are drawn in Fig. 3a as a function of $h_{p}$. For WZ_oS and KD_oS variants, runs with $h_{p}=8.4 \mathrm{~cm}$ (border conditions 1 and 5 in Table 3) were excluded, since the velocities were higher than $120 \mathrm{~cm} / \mathrm{s}$, i.e., higher than the operation range of the micro-current meters. Irrespective of the propeller type, three groups of data can be identified in Fig. 3a, and may be arranged according to their magnitude of velocity: one group for free propellers $\left(\mathrm{KoO} \_\mathrm{oS}\right.$ and WO_oS); one for propellers with ship stern and with rudder (KD and WZ); and one for propellers without ship stern but with rudder (KD_oS and WZ_oS). As a reference, best-fit power functions have been drawn in Fig. $3 \mathrm{a}$ for data pertaining to the same variant, except for the free propellers. In this latter case, the curve resulting from applying Eq. (1) and Eq. (3) has been drawn in the graphic, showing that for these two variants, which describe conditions without additional elements that would influence the diffusion of the jet, the theoretical results slightly underestimate the experimental values (by roughly $7 \mathrm{~cm} / \mathrm{s}$ ), irrespective of the propeller type.

The same data from Fig. 3a have been drawn in Fig. 3b, but using the non-dimensional quantities involved in Eq. (3) in order to identify the best-fit values for the $E$-coefficient. The coefficients obtained are summarized in Table 4, and compared with the recommended values in the literature, for each of the geometrical variants. For the free propellers the bestfit values are close to those found in the literature, and the same applies for the KD variant (SS1). Conversely, for WZ (SS2) the fitted coefficient is $60 \%$ the value found in the literature, while for $\mathrm{KD} \_\mathrm{oS}$ the recommended value is $60 \%$ smaller than the fitted one.
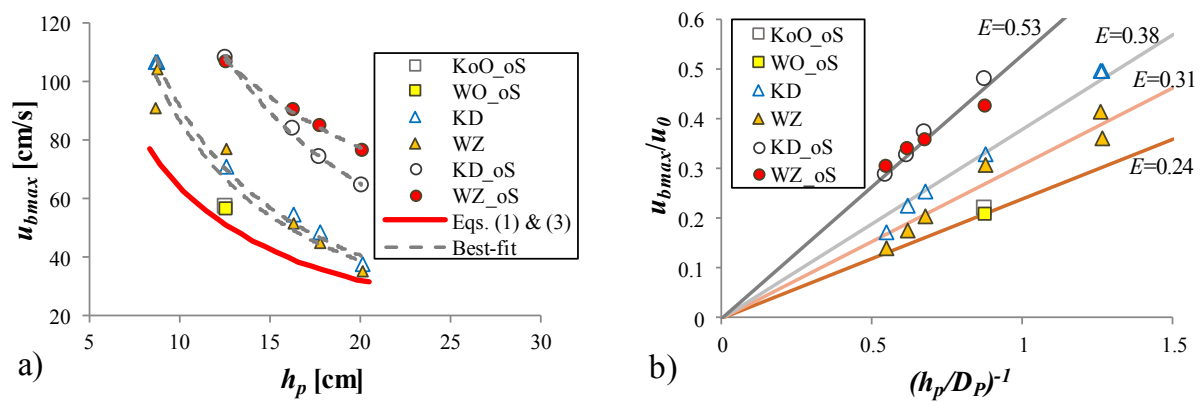

Fig. 3. (a) Maximum velocities near the bottom as a function of the propeller axis height above the bed; (b) same variables as in (a), but normalized by measured $u_{0}$ and $D_{P}$, respectively.

From Fig. 3, it can be deduced that the maximum velocity near the bottom is higher when a free propeller is equipped with a rudder, either central or double. Nevertheless, likely due to added jet diffusion, the effect of the ship stern is that the maximum bed velocity decreases by as much as $22 \%$ with a central rudder and $16 \%$ with a double rudder.

\section{Discussion and Conclusions}

Results from laboratory experiments to study the time-dependent scour and the flow field induced by two propellers of inland vessels, for a manoeuvring situation, have been 
presented in this work. It was found that the formula for the efflux velocity derived from axial momentum theory performed well with all tested conditions, except for ducted propellers. For this case, velocities were underestimated by up to $16 \%$. The results showed as well that a simple formula recommended in recent codes of practice and guidelines ([7]) for the maximum velocity induced by a propeller jet on the bed, performed well for free propellers, i.e., propellers without nozzle, rudder or ship stern. Conversely, for propellers provided with nozzle or rudder, or under a ship stern of an inland barge, the formula estimates showed large deviations from the measured values. Accordingly, the relations for the efflux velocity and the maximum velocity near the bed need to be improved. This is a critical point for propeller induced scour estimations, since scour formulas rely on predictions of the efflux velocity and the maximum near bed velocity.

Scour experiments with a Kaplan propeller with Kort nozzle, under ship stern and with double rudder, resulted in roughly the same equilibrium maximum scour depth as similar runs with a Wageningen propeller, under ship stern and with central rudder. However, with the Wageningen propeller much longer times were required to reach equilibrium scour. These results were consistent with the velocity measurements close to the bottom. Jet velocities near the bed were larger with the Kaplan than with the Wageningen propeller, for low heights $h_{p}$ between the propeller and the bed (see KD and WZ in Fig. 3); however, as this height increased, differences between the two propellers decreased, so that bed velocities converged to almost the same values when the height was roughly higher than $18 \mathrm{~cm}$. This means that for an initially high bed level, the Kaplan propeller will induce higher velocities on the bed than the Wageningen propeller, and thus the erosion will progress faster with the former; but as the scour depth increases, and the height between the propeller and the bed increases too, the bed velocity with the two propellers will tend to the same value. In this way the time development of scour would follow different paths with the two propellers, but the equilibrium bed scour would be of similar magnitude at the end.

\section{References}

1. H. J. Verhey, 8th Int. Harbour Congress, Antwerp, Belgium (1983)

2. G. A. Hamill, PIANC-Bulletin 62: 85-110 (1988)

3. K. Römisch, III Int. Seminar on Renovation and Improvements to Existing Quay Structures, Gdansk, Poland (1993)

4. M. Fuehrer, K. Römisch, Proc. 24th PIANC Congress, Leningrad, Sects 1-3, (1977)

5. H. G. Blaauw, E.J. van de Kaa. Delft Hydraulics Laboratory (1978)

6. H. Oebius, Mitteilungsblatt der Bundesanstalt für Wasserbau, 82: 7-22 (2000)

7. BAW, BAW codes of practice and guidelines. Federal Waterways Engineering and Research Institute, Germany (2010)

8. W. J. Rankine Trans, RINA (6) (1865)

9. M. L. Albertson, Y.B. Dai, R.A. Jensen, H. Rouse, Trans. ASCE 115: 639-697 (1950)

10. M. Fuehrer, K. Römisch, G. Engelke. Proc. 25th PIANC-Congress, Edinburgh: 29-50 (1981)

11. S. T., Maynord, Proc. of the Ports '98 Confer., Long Beach, USA, 1074-1093 (1998)

12. P. Geisenhainer, J. Aberle. Experimental and computational solutions of hydraulic problems. Ed. P. Rowinski, Springer, 119-131 (2013)

13. LWI Leichtweiß-Institut für Wasserbau, Bericht 946, TU Braunschweig, in German, unpublished (2007)

14. K. Felkel, H. Steinweller, Wasserwirtschaft, 62(8), 243-249, in German (1972) 